\title{
PEDAGOGÍA Y FARISEÍSMO: SOBRE LA ELEVACIÓN Y EL REBAJAMIENTO EN GOMBROWICZ
}

\author{
JORGE LARROSA \\ ¿Conocéis esa sensación de empequeñecer dentro de alguien? \\ (Witold Gombrowicz. Ferdydurke)
}

\begin{abstract}
RESUMEN: Este artículo se presenta como una aproximación entre pedagogía y fariseísmo. Para Jacotot-Rancière, la pedagogía produce al ignorante y a su inteligencia inferior. Por eso ni la teoría ni la práctica de la instrucción pueden soportar la tesis radical de la igualdad de las inteligencias. Se trata aquí de una invitación a la lectura de Gombrowicz para mostrar los juegos de la elevación y el rebajamiento que están implícitos en las teorías y en las prácticas de la formación.
\end{abstract}

Palabras clave: Gombrowicz. Formación. Rebajamiento.

\section{Pedagogy and pharisaism:}

ON THE ELEVATION AND FALL IN GOMBROWICZ

ABSTRACT: This paper presents an approximation between pedagogy and pharisaism. For Jacotot-Rancière, pedagogy produces an ignorant and inferior intelligence. Because of this, neither the theory nor the practice of instruction can accept the thesis of the equality of the intelligences. This paper offers an invitation to the reading of Gombrowicz to show how the games of elevation and debasement are implicit in the theories and practices of "formation"

Key words: Gombrowicz. Formation. Debasement.

Professor Titular de Filosofía de la Educación en la Universidad de Barcelona. E-mail: jlarrosa@d5.ub.es

Educ. Soc., Campinas, vol. 24, n. 82, p. 289-298, abril 2003

Disponível em <http://www.cedes.unicamp.br> 
7 acques Rancière usó la voz de Jacotot para mostrar que, desde el punto de vista de la instrucción, la pedagogía atonta, es decir, que enseña y hace aprender (se constituye como una teoría y una práctica de la enseñanza y del aprendizaje), pero produciendo, en esas mismas operaciones, tanto la distancia en el saber como la desigualdad de las inteligencias. Además, Rancière-Jacotot muestran cómo el orden pedagógico del atontamiento es consustancial a un orden social y político que persigue la igualdad al mismo tiempo que produce la desigualdad y que aspira a la libertad produciendo la dominación. Siguiendo esa estela, voy a introducir aquí a otro excéntrico, a Witold Gombrowicz, para mostrar que, desde el punto de vista de la formación, la pedagogía, solidaria también en eso con el orden social, produce distancias y desigualdades que no son ya de orden cognoscitivo o de orden intelectual sino de orden personal o moral.

Si la instrucción tiene que ver con lo que se sabe, la formación tiene que ver con lo que se es. Si en un caso se trata de yo sé lo que tú no sabes... y sé lo que tú deberías saber... luego puedo y debo ense , o también de yo sé cómo funciona una inteligencia... y sé cómo debería funcionar la tuya... por lo tanto puedo y debo dirigirla, en el otro se trata de yo soy mejor que tú... y soy lo que tú deberías ser... luego puedo y debo formarte. En ambos casos, la pretensión de la igualdad, la buena conciencia igualitaria, presupone la desigualdad. Y ésta tiene por origen el menosprecio - intelectual en un caso, moral en otro - y su correlato necesario, la soberbia: si todos supieran lo que yo sé, si todos pensaran como yo pienso, si todos fueran como yo... sin duda el mundo sería mejor. Es así como muchos proyectos de mejora de la humanidad se formulan desde una perspectiva vertical en la que las posiciones de lo bueno y de lo malo, de lo alto y lo bajo, de lo superior y lo inferior, quedan retóricamente definidas y moralmente marcadas, al tiempo que disponibles para ser ocupadas por distintos individuos. De lo que se trata, entonces, es de situarse en una posición segura y asegurada que permita hablar y actuar desde arriba. Y eso significa, en la modernidad, hablar y actuar desde una instancia de Poder, básicamente el Estado. Ya el pícaro español por excelencia, el Lazarillo de Tormes, se esforzaba inútilmente en ser de los buenos e identificaba la entrada en ese grupo privilegiado con tener un empleo de la Iglesia o de la Corona. Y no deja de ser significativo que, cuando consigue ese empleo, sea el del pregonero que encabeza el desfile de los malos voceando la inmoralidad de los condenados a galeras o a vergüenza pública.

Podemos encontrar la doble figura del menosprecio y de la soberbia, magníficamente condensada, en el retrato del fariseo de la 
parábola evangélica: "te doy gracias, Señor, porque no soy como los otros hombres..., porque no soy como ese publicano". El tipo humano del fariseo muestra ahí cómo su esencia moral se produce en la relación, en la comparación, en lo que Sánchez Ferlosio llama "edificación por contraste", es decir, en la construcción de su propia bondad a través de la maldad del otro: el fariseo "necesita del malo y lo cuaja ontológicamente en el aire con una sobrehumana maldición para constituirse él, por contraposición, en bueno" (1992, p. 132).

Enemigo de toda ambigüedad moral, especialista en mirar desde lo alto, y enemigo sobre todo de cualquier sospecha de la íntima solidaridad entre el campo de las blancas y el de las negras, el fariseo se coloca a salvo de toda contaminación. El fariseo necesita del mal, para definirse contra él, para separarse de él, para sentirse lejos de él, para ponerse a salvo:

(...) el fariseo es un bueno cuyas acciones suben cuanto más bajan las de ese eterno otro puesto enfrente por correlato necesario de su propio ser. $\mathrm{Su}$ bondad es un globo que se hincha y magnifica con el aire insuflado por el fuelle de la maldad ajena en el vacío interior de sus entrañas. Por eso acude ávidamente a cargarse de razón al surtidor de la iniquidad ajena. (Idem, ibid.).

Del mismo modo que, para elevarse intelectualmente y asegurar su posición, el maestro atontador de Jacotot-Rancière necesita disminuir al otro, establecer su ignorancia, definir el funcionamiento inferior de su inteligencia, también la autoelevación moral del fariseo y su correlato pedagógico, la formación, funcionan por rebajamiento. Sabemos desde Platón que a la pedagogía le es constitutiva una mirada desde arriba. Y, para que esa mirada sea posible, tiene que fabricar retórica y ontológicamente un abajo: la infancia, el pueblo, los estudiantes, los emigrantes, los inmorales, los pobres, los desempleados, los trabajadores, los consumidores, los jóvenes, los maestros, los ignorantes, los salvajes..., los otros..., definidos siempre por una distancia: por lo que les falta, por lo que necesitan, por lo que no son, por lo que deberían ser, por su resistencia a someterse a las buenas intenciones de los que tratan de que sean como deberían ser. De hecho, ubicarse en el discurso pedagógico significa, en muchos casos, adquirir una cierta legitimidad y una cierta competencia para mirar a los otros desde arriba, para hablar de ellos, y para lanzar sobre ellos ciertos proyectos de reforma o de mejoramiento. Quizá sea por eso que la pedagogía está atravesada de fariseísmo. De ahí esta invitación a la lectura de Gombrowicz, sobre todo de su Ferdydurke, ${ }^{1}$ en paralelo a la de Rancière-Jacotot, para una consideración de la lógica social y pedagógica de la elevación y el rebajamiento. 
¿Por qué Gombrowicz? Primero, por el modo como encarna la distancia respecto a la forma, la conciencia de su carácter inauténtico, falso, artificial. En segundo lugar, por la aguda percepción de cómo el juego de la formación descansa sobre una desigualdad moral fabricada y permanentemente reproducida. Tanto en sus novelas como en sus obras de teatro o en sus diarios, Gombrowicz elabora su propia patología: toma su yo - su rareza, su excentricidad, su indefinición, su anomalía, su imposibilidad, su inexistencia - como materia de disección y experimentación. Podemos encontrar ahí el niño en el castillo de Maloszyce, incapaz de ocupar Su Lugar Propio en esa sociedad rural y estúpidamente aristocrática en la que se cultiva la soberbia de casta y la absoluta división entre amos y siervos. O al escolar en el Instituto San Estanislao de Kotska, fascinado y a la vez humillado por sus nobles y sofisticados compañeros, dedicándose a ciertas lecturas lamentables e incapaz de entrar en lo que ahí se daba como Gran Literatura. $\mathrm{O}$ al joven provocador del café Ziemianska que nunca puede sentarse en las mesas en las que se discutían los Problemas Importantes. O al estudiante de la Facultad de Derecho, aprobando los cursos sin ningún convencimiento e incapaz de identificarse con esos compañeros que ya estaban elaborando su superioridad y la conciencia de su destino como Dirigentes al Servicio del Estado y de la Patria. O al observador irónico de las formas sociales ya decadentes y un tanto ridículas a las que se aferraba una burguesía en declive como si en ellas pudiera encontrar salvación en un mundo que se derrumbaba. $\mathrm{O}$ al viajero polaco rumiando su inferioridad cultural frente a las Gran Cultura de París o a la Gran Historia de Roma. O al desertor de la guerra incapaz de estar a la Altura de las Circunstancias. O al hombre aterrorizado por el espectáculo de esas muecas uniformadas tan seductoras como monstruosas con las que Europa se dirigía a la catástrofe. $\mathrm{O}$ al emigrante en Argentina, ya sin ninguna voluntad de continuar siendo Polaco e incapaz de convertirse en Argentino, entre otras cosas porque eso supondría también ser un Europeo que nunca conseguirá ser Europeo. $\mathrm{O}$ al escritorzuelo que nunca entra, por imposibilidad y por desprecio, en los cenáculos literarios en los que se reúnen los Cultos y los Exquisitos de Buenos Aires. $\mathrm{O}$ al incurablemente escéptico frente a todas las formas de creencia colectiva que luchaban por imponer la Idea Superior (la Democracia, el Socialismo, el Nacionalismo). O al aspirante al Amor Familiar y Eterno incapaz de evitar el sentirse atraído por la promiscuidad homosexual de los barrios bajos. $\mathrm{O}$ al inmaduro permanente que nunca puede llegar a ser Adulto. $\mathrm{O}$, al final de su vida, cuando le había llegado el éxito y la fama, al hombre enfermo y cansado 
incapaz de ser ese Artista, Intelectual y Escritor Reconocido llamado Gombrowicz.

Atraído y a la vez asqueado y rechazado por lo alto, atrapado por la ambigua fascinación de lo bajo, cultivador obsesivo de todas las formas del egotismo y de la extravagancia, outsider irremediable, Gombrowicz experimentó, tanto en su carne como en su escritura, el esquema de la superioridad-inferioridad y el juego perverso de la elevación-rebajamiento en lo sexual, lo cultural, lo social, lo político, lo moral, lo pedagógico, lo profesional, lo intelectual, lo personal. Porque no quiso, o no pudo, o no le dejaron ser alguien, Gombrowicz nunca aceptó ninguna abstracción identitaria, nunca se identificó con ningún nosotros, y se mantuvo en el limbo de lo pseudo: pseudonoble, pseudoestudiante, pseudopolaco, pseudoexiliado, pseudoescritor, pseudointelectual, pseudointeligente, incluso pseudovanguardista o pseudoprovocador.

Incapaz de adscribirse a ninguna de las Tribus Superiores, refractario a cualquier dentro y, por tanto, habitando el territorio intermediario del entre, experto en la parodia y en el camaleonismo, imposibilitado para ser nada y, por ello, capaz de fingir cualquier cosa, "favorable a todas las formas, incluso las más estrafalarias, como esas figuritas de gutapercha que permiten ser modeladas indefinidamente y con las que se puede fabricar el monstruo más espantoso". (Gombrowicz, 1991, p. 40), se hizo capaz de denunciar a través de la sátira, de la parodia, de la burla más mordaz, la mentira de los que se valen de cualquiera de las formas prefabricadas de la superioridad para halagar su vanidad, para ocultar su estupidez, para protegerse de la vida y para jugar de manera oportunista al juego de las posiciones y las jerarquías, al juego de la autoelevación por menosprecio, inferiorización y rebajamiento del otro, al juego del fariseísmo en suma.

¿Por qué Ferdydurke? Primero, porque Ferdydurke no es ni una novela ni un ensayo ni un manifiesto (aunque podría ser una parodia de todos esos géneros) sino un panfleto, una descarada bomba verbal, un manual de instrucciones para la guerra de guerrillas cultural. Además, porque Ferdydurke puede ser leída como una novela de formación llevada al absurdo. Por último, porque, al igual que el libro de Rancière-Jacotot, Ferdydurke aniquila cualquier forma de buena conciencia, imposibilita cualquier mirada desde arriba y cancela así cualquier alternativa medianamente sensata que pueda venderse en ese mercado de lo que habría que hacer con los otros en el que los mejoradores de la humanidad compran y venden sus mercancías. En Ferdydurke todo está llevado al límite del ridículo: los ideales se vuelven grotescos y sangrientos, los valores 
aparecen como irreales y estúpidos, las identidades muestran su lado servil, su rigidez y su acartonamiento, las construcciones morales exhiben su falsedad y su carácter destructivo y autodestructivo, las formas son llevadas hasta el extremo de lo grotesco. Ferdydurke es implacable contra todas las modalidades del darse importancia, contra todas las formas de elevación. E implacable también contra todas las formas de empequeñecimiento que son su correlato. Su blanco son los altos, pero también los que consienten en su propio rebajamiento, quizá para rebajar después a otros. Pero no se limita a ser un simple atentado a la hipocresía, a los convencionalismos o a las jerarquías. Ferdydurke es toda una antropología del absurdo humano y, a la vez, toda una teoría de las poéticas y las políticas de la falsificación: una reflexión sobre las trampas de la formación de la subjetividad y sobre las perversiones de los juegos de la intersubjetividad. Y una reflexión tan acerada que incluso se anula a sí misma como Reflexión, como Teoría, como Obra, como Literatura, como Arte, como Valor. Ferdydurke no quiere ser nada porque sólo así puede librarse de entrar como una pieza más en el sistema del cual revela los dispositivos.

Gombrowicz resume así el tema de su libro:

(...) Ferdydurke no sólo se ocupa de lo que podríamos llamar la inmadurez natural del hombre, sino ante todo de la inmadurez lograda por medios artificiales: es decir que un hombre empuja al otro en la inmadurez y que también - ¡qué raro! - del mismo modo actúa la cultura (...) ... el supremo anhelo de Ferdydurke es encontrar la forma para la inmadurez. Podemos en forma madura expresar la inmadurez ajena, pero con eso no logramos nada (...). Aún si nos pusiéramos a analizar y confesar nuestra propia insuficiencia, siempre lo haríamos en forma madura. (2001, p. 17-18)

O, en otro lugar:

(...) si la Forma nos deforma, entonces el postulado moral exige que saquemos las consecuencias pertinentes. Ser yo mismo, defenderme contra la deformación, mantener las distancias respecto de mis sentimientos, de mis pensamientos más íntimos, en la medida en que ni los unos ni los otros me expresan adecuadamente. Esa es la primera obligación moral. Es sencillo, ¿verdad? Pero he aquí el quid fatal: si soy siempre artificial, siempre definido por los demás hombres y por la cultura, así como por mis propias necesidades formales, ¿¿ónde buscar mi "yo"? ¿Quién soy realmente, y hasta qué punto soy? Esta cuestión me perturbaba en la época en que escribía Ferdydurke. No he encontrado más respuesta que ésta: ignoro cuál es mi forma, lo que soy, pero sufro cuando se me deforma. Así pues, al menos sé lo que no soy. $\mathrm{Mi}$ "yo" no es sino la voluntad de ser yo mismo. (1991, p. 82) 
Para Gombrowicz no existe la espontaneidad, ni la simplicidad, ni la autenticidad. Es más: las percibe como formas sofisticadas y pretenciosas de la falsificación y del fariseísmo. Sus burlas al existencialismo son, en ese sentido, altamente mordaces:

Tal vez no me hallaba lejos de elegir la existencia que ellos denominan auténtica, al contrario de esa vida fútil, inmediata y temporal que llaman banal, pues la presión del espíritu de seriedad nos oprime con fuerza desde todas partes. Hoy, en este severo tiempo actual, no hay pensamiento ni arte que no nos griten con voz destemplada: ¡no te evadas, no juegues, asume la partida, responsabilízate, no sucumbas, no huyas! Bien. Claro que también yo preferiría, a pesar de todo, no mentirme sobre mi propia existencia. Intenté entonces conocer esta vida auténtica, ser absolutamente leal ante la existencia. Pero no me fue posible. No me fue posible por la razón de que tal autenticidad resultó más ficticia que todos mis jueguitos, vueltas y saltos juntos. (2001, p. 101)

El individuo sólo puede ser alguien en el interior de alguna configuración formal. El hombre es creador de formas y, a la vez, es creado por ellas. Cualquier formación es deformación. Somos deformados por la forma, deformamos a los otros y somos deformados por ellos. Y esos procesos de formación y deformación mutua funcionan muchas veces en un orden vertical. El hombre no puede elevarse ni tratar de elevar a los otros si no es rebajando. Ferdydurke contiene varios de esos juegos de la falsificación y el rebajamiento. La escena en la que Pimko, el Maestro, exhibe su maestría requetemagistral para infantilizar con ella al narrador y convertirlo en alumno. La escena en que Pimko exhibe su fe pedagógica en la pureza y la inocencia de la juventud para, ayudado por las madres que observan a través de los agujeros de la valla, inocentizar a los muchachos que juegan en el patio de la escuela. La escena de la lucha entre el adolescente que pretende adolescentizar a los muchachos y el muchacho que quiere muchachear a los adolescentes y que culmina en un delirante duelo de muecas. La descripción de la forma vacía del cuerpo pedagógico que, justamente para ser pedagógico, tiene que carecer de cualquier contenido. El relato de la clase de la literatura en la que el enjuto profesor lucha desesperadamente contra el nopodermiento de la mayoría de los alumnos que no pueden conmoverse como deberían conmoverse por los elevados y conmovedores sentimientos de los grandes poetas nacionales. El desfile de los diferentes ideales de juventud que se disputan la formación de los jóvenes. La clase de latín en la que, pese a todas las evidencias en contra, el profesor confiado confía en las virtudes formativas de la materia que enseña y, frente al nopodermiento que se 
apodera de la clase, mantiene erguida su confianza en los poderes enriquecedores y perfeccionadores de las conjugaciones latinas. El encuentro del narrador con la colegiala y su aire colegial, con la joven Juventona perfectamente moderna en su perfecto y juvenil modernismo, y sus tentativas desesperadas para escapar de los efectos juvenilizadores y modernizadores que le causa. Etc.

$\mathrm{Y}$, en el medio de ese paroxismo de interformaciones e interdeformaciones, de superioridades que producen inferioridades y se nutren de ellas (y al revés), de elevaciones y rebajamientos, en el medio de todas esas abstracciones, de toda esa irrealidad, de toda esa movilización demoníaca de falsificaciones, la única posibilidad es la de la distancia de la forma. Una distancia que sólo será tal, y no otra versión del fariseísmo, si se toma en nombre de la vida, en nombre de lo ambiguo, lo inacabado, lo indefinido, lo misterioso, lo promiscuo y lo vago de la vida:

(...) liberaos de la forma. Dejad de identificaros con lo que os define. Tratad de huir de toda expresión vuestra. Desconfiad de vuestras opiniones. Tened cuidado de las fes vuestras y defendeos de vuestros sentimientos (...) Pronto nos daremos cuenta de que ya no es lo más importante morir por las ideas, estilos, tesis, lemas y credos, ni tampoco aferrarse y consolidarse en ellos, sino esto: retroceder un paso y distanciarnos frente a todo lo que se produce sin cesar en nosotros (...). Pronto empezaremos a temer a nuestras personas y personalidades porque sabremos que esas personas no son del todo nuestras, Y, en vez de vociferar y rugir: Yo creo eso, yo siento eso, yo soy así, yo defiendo eso, diremos con más humildad: A través de mí se cree, se siente, se dice, se hace, se piensa, se obra... El vate repudiará su canto. El jefe temblará ante su orden. El sacerdote temerá al altar, la madre enseñará a su hijo no sólo principios, sino también como defenderse contra ellos para que no le hagan daño. Y, por encima de todo, lo humano se encontrará algún día con lo humano. (2001, p. 108-109)

Para que lo humano encuentre a lo humano, hay que buscar la propia libertad y el encuentro con los otros en el juego de las formas, pero manteniéndose a distancia. Hay que cultivar la incredulidad y el escepticismo con los demás y con uno mismo, provocar y asumir las contradicciones (sobre todo las propias), ocupar irónicamente las formas para destruirlas desde dentro (y autodestruirse con ellas), moverse permanentemente de una forma a otra, aprender a expresar nuestra ignorancia, nuestra inmadurez, nuestra estupidez, nuestra bajeza, evitar todo contraste vertical si no es para movilizar lo bajo contra lo alto, negarse a ser rebajados... a lo mejor así, algún día, los intelectuales podrán salir de su 
intelectualidad, los maestros de su maestridad, los alumnos de su alumnidad, los cultos de su cultidad, los políticos de su politicidad, los artistas de su artisticidad, los buenos de su bondad, los malos de su maldad, los superiores de su superioridad, los inferiores de su inferioridad, los individuos de su individualidad, las personas de su personalidad... sólo así se abrirá un camino hacia la realidad, hacia la vida. Al final de Ferdydurke, el héroe se siente cansado y extraño, pero todavía es capaz de besar y de dejarse besar, y de sentir la fuerza vivificante de lo humano que se encuentra con lo humano:

(...) y me acercó su facha. Y a mí me faltaron las fuerzas, el sueño sumergió la vela y no podía; tuve que besar su facha con mi facha, pues ella con su facha besó mi facha. ¡Y ahora, venid, fachas! ¡No, no me despido de vosotras, extrañas y desconocidas fachadas de extraños, desconocidos fachendos que me vais a leer; salud, salud, graciosos ramilletes de partes, justamente ahora que empieza! Llegad y acercaos a mí, comenzad vuestro estrujamiento, hacedme una nueva facha para que de nuevo tenga que huir de vosotros en otros hombres, y correr, correr, correr a través de toda la humanidad. Pues no hay huída ante la facha sino en otra facha, y ante el hombre sólo podemos refugiarnos en otro hombre. Y, ante el culito, ya no hay ningua huída. ¡Perseguidme si queréis! Huyo con mi facha en las manos. (2001, p. 313)

Como dice Rancière en el Prefacio a la edición brasileña de El maestro ignorante, es difícil hacer escuelas, programas y reformas después de haberse tomado en serio la excentricidad de Jacotot. Pero nadie ha dicho que los libros tengan que servir para que las cosas sean fáciles. El reto está, naturalmente, en hacer escuelas, programas y reformas habiendo aprendido esa lección que ni se explica ni puede explicarse, la de la igualdad de las inteligencias. Una lección que nunca aprenderán ni los curas, ni los políticos, ni los policías, ni esa mezcla de curas, políticos y policías que tanto abunda entre los pedagogos. Es a ellos a los que hay que hacer las cosas difíciles. Habiéndose tomado en serio la excentricidad de Gombrowicz, es difícil seguir dándose importancia o seguir tomándose a uno mismo en serio utilizando para eso cualquier valor, cualquier ideal, cualquier superioridad intelectual o moral, cualquier máscara de fariseo. Pero nadie ha dicho que los libros sirvan para que los importantes puedan darse importancia. Sin embargo, quizá se puede trabajar apasionadamente en la contingencia, la relatividad y la finitud, en la estupidez y en la bajeza, contemplando la realidad desde dentro y no desde arriba, encontrando lo humano no en abstracciones retóricas y vacías, sino en lo humano y desde lo humano. 
Para el combate contra el fariseísmo, propongamos pues una alianza entre el club de los jacototianos y el club de los ferdydurkistas. Por una instrucción que no atonte: todas las inteligencias son iguales. Por una formación que no rebaje: cuanto más inteligente, más estúpido; ${ }^{2}$ cuanto más alto, más bajo. En fin, que no somos nadie (ni queremos serlo).

Recebido e aprovado em fevereiro de 2003.

\section{Notas}

1. Ferdydurke se publicó por primera vez en Polonia en 1937, pero fue casi totalmente ignorada. Tras el deshielo postestalinista, reapareció en 1957, pero fue prohibido al año siguiente, y así permaneció hasta 1986. En español, se publicó por primera vez en Buenos Aires en 1947.

2. Ese es el título de un fragmento del Diario de Gombrowicz que fue publicado aparte y que funcionó como un manifiesto de la subversión cultural.

Referencias bibliográficas

GOMBROWICZ, W. Cuanto más inteligente se es, más estúpido. In: Gombrowicz,W.; Dubuffet, J. Correspondencia. Barcelona: Anagrama, 1971.

GOMBROWICZ, W. Testamento: conversaciones con Dominique de Roux. Barcelona: Anagrama, 1991.

GOMBROWICZ, W. Diario argentino. Buenos Aires: Adriana Hidalgo, 2001.

GOMBROWICZ, W. Ferdydurke. Barcelona: Seix Barral, 2001.

GOMBROWICZ, W. Prólogo para la primera edición castellana (1947). In: Gombrowicz, W. Ferdydurke. Barcelona: Seix Barral, 2001.

RANCIERE, J. La nuit des proletaires. Paris: Fayard 1981.

RANCIERE, J. La philosophie et ses pauvres. Paris: Fayard 1985.

RANCIERE, J. Courts vouages au pays du peuple. Paris: Seuil 1990.

RANCIERE, J. El maestro ignorante: cinco lecciones sobre la emancipación intelectual. Barcelona: Laertes, 2003.

SANCHEZ FERLOSIO, R. Restitución del fariseo. In: . Ensayos y artículos. Barcelona: Destino, 1992. v. 1.

SLOTERDIJK, P. El desprecio de las masas: ensayo sobre las luchas culturales de la sociedad moderna. Valencia: Pre-textos, 2002. 